\title{
Erratum to: Interactive $X$-ray and proton therapy training and simulation
}

Felix G. Hamza-Lup ${ }^{1}$ - Shane Farrar ${ }^{1}$ - Erik Leon ${ }^{1}$

Published online: 5 August 2015

(c) CARS 2015

\section{Erratum to: Int J CARS \\ DOI 10.1007/s11548-015-1229-7}

The author would like to correct the errors in the publication of the original article. The corrected details are given below for your reading.

In the Reference section, reference [21] should be reference [25] and reference [25] should be reference [21].

The online version of the original article can be found under doi:10.1007/s11548-015-1229-7.

$凶$ Felix G. Hamza-Lup

Felix.Hamza-Lup@armstrong.edu

1 Computer Science and Information Technology, Armstrong State University, Savannah, GA, USA 